Portland State University

PDXScholar

5-15-1996

\title{
Influence of Articulation and Phonology Intervention on Children's Social and Emotional Characteristics
}

Tracy Lynn Carlisle

Portland State University

Follow this and additional works at: https://pdxscholar.library.pdx.edu/open_access_etds

Part of the Speech and Rhetorical Studies Commons

Let us know how access to this document benefits you.

\section{Recommended Citation}

Carlisle, Tracy Lynn, "Influence of Articulation and Phonology Intervention on Children's Social and Emotional Characteristics" (1996). Dissertations and Theses. Paper 5246.

https://doi.org/10.15760/etd.7119

This Thesis is brought to you for free and open access. It has been accepted for inclusion in Dissertations and Theses by an authorized administrator of PDXScholar. Please contact us if we can make this document more accessible: pdxscholar@pdx.edu. 


\section{THESIS APPROVAL}

The abstract and thesis of Tracy Lynn Carlisle for the Master of Science in Speech Communication: Speech and Hearing Science were presented May 15, 1996, and accepted by the thesis committee and the department.

COMMITTEE APPROVALS:

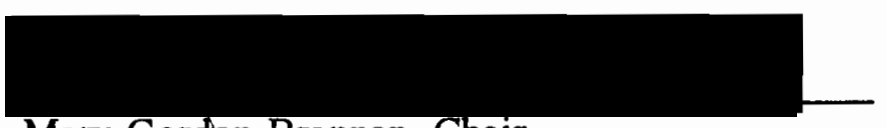

Mary Gordon-Brannan, Chair

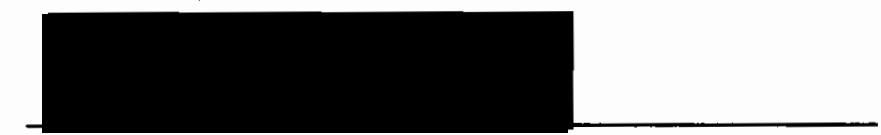

Rhea Paul
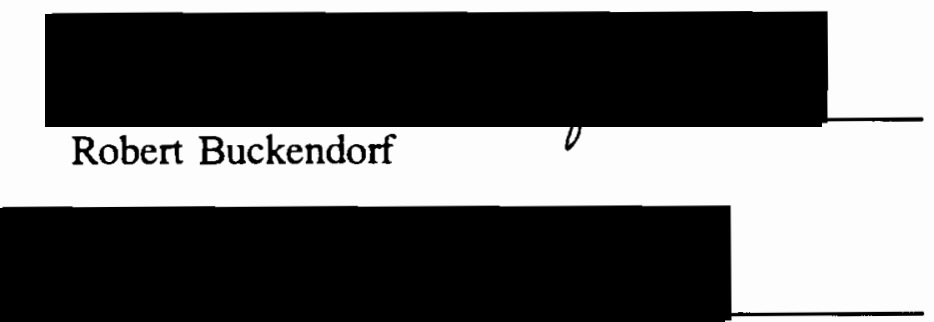

Ann Fullerton

Representative of the Office of Graduate Studies

DEPARTMENT APPROVAL:

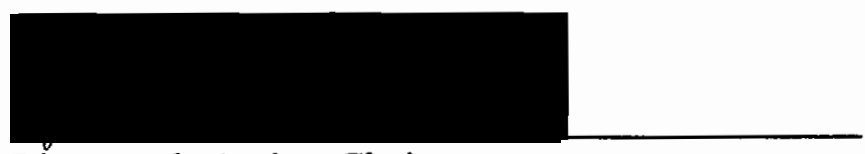

Rhea Paul, Acting Chair

Department of Speech Communication

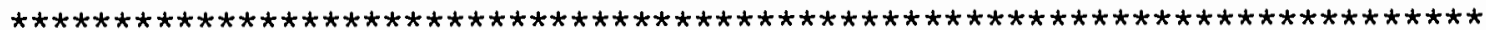

ACCEPTED FOR PORTLAND STATE UNIVERSITY BY THE LIBRARY

by on

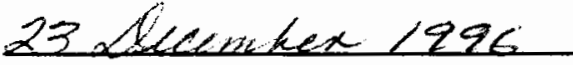




\begin{abstract}
An abstract of the thesis of Tracy Lynn Carlisle for the Master of Science in Speech Communication: Speech and Hearing Science presented May 15, 1996.
\end{abstract}

Title: Influence of Articulation and Phonology Intervention on Children's Social and Emotional Characteristics

It would be useful to obtain information about social and emotional characteristics in children who are receiving articulation/phonological intervention in order to assess the effectiveness of various treatment approaches from a social/emotional perspective. The purpose of this study was to determine whether or not articulation and phonological intervention influences children's social and emotional characteristics as perceived by their parents and, if so, which articulation approach (traditional vs. phonological cycling) results in more improvement in different domains of social and emotional characteristics. The specific social and emotional characteristics explored in this study are social skills, communication, independence, self-esteem, and domestic responsibility as assessed by the Affective Behavior Scales for the Disabled-Modified (ABSD-Modified, Brannan, 1991).

In this study, each of the subject's parents completed a rating scale of social and emotional characteristics of their child at the beginning of intervention and again 
after 20 weeks of intervention. The scores for the five social and emotional domains were compared for differences prior to and following intervention. Additionally, the amount of improvement for those social and emotional characteristics was compared between the two groups, one group receiving traditional articulation intervention and the other group receiving a phonological cycling approach.

Data analysis revealed no statistically significant difference between pre- and post-intervention subscale scores for the traditional articulation intervention group and for the phonological cycling intervention group combined. The results also indicated no statistically significant difference in the amount of change in social and emotional characteristics between the two groups of subjects. However, the research data did show trends toward the statistically significant level of .05 in the social/emotional domains of self-esteem $(p=.097)$ and communication $(p=.091)$ for the phonological cycling group. Trends toward the statistically significant level in the two domains of self-esteem and communication suggest that articulation/phonological intervention may influence other areas in the individual's life. Therefore, further investigation of the research questions posed for this study is warranted. 
INFLUENCE OF ARTICULATION AND PHONOLOGY

INTERVENTION ON CHILDREN'S SOCIAL

AND EMOTIONAL CHARACTERISTICS

by

TRACY LYNN CARLISLE

A thesis submitted in partial fulfillment of the requirements for the degree of

MASTER OF SCIENCE

in

SPEECH COMMUNICATION:

SPEECH AND HEARING SCIENCE

Portland State University

1996 


\section{ACKNOWLEDGEMENTS}

I want to share my greatest appreciation with my advisor, Mary GordonBrannan, for her continual support and guidance. She always offered kind words about the development of my thesis and gentle reassurance that this project would come together. Our weekly meetings and her availability to listen to my concerns allowed me to finish this project on time. I also want to thank her husband, Steve Brannan, for providing the questionnaire necessary to conduct this project.

A special thank you to Bob Buckendorf for his willingness and cooperation in allowing me to participate in his dissertation study. In my eyes, he did above and beyond the call of duty by not only providing the subjects for my project but also many bright smiles and a generous amount of positive feedback. He was a constant figure of direction and encouragement.

I would like to extend a warm thank you to all of the graduate clinicians who administered my questionnaire before and after intervention services with the children who participated in this project.

I want to especially thank my husband, Joseph Carlisle, for his love, support, and understanding throughout the development of this project. He was always open to listen to my ideas about the course of this project and share positive words that helped me complete my thesis. 


\section{TABLE OF CONTENTS}

PAGE

\section{CHAPTER}

I INTRODUCTION AND STATEMENT OF PURPOSE $\ldots \ldots \ldots \ldots 1$

Introduction $\ldots \ldots \ldots \ldots \ldots \ldots \ldots \ldots$

Statement of Purpose $\ldots \ldots \ldots \ldots \ldots \ldots \ldots$

II REVIEW OF THE LITERATURE $\ldots \ldots \ldots \ldots \ldots \ldots \ldots$

Traditional Speech Sound Analysis . . . . . . . . . 5

Phonological Processes $\ldots \ldots \ldots \ldots \ldots \ldots \ldots$

Effects of Communication Disorders on Social and Emotional Behaviors .............8

Assessment of Social and Emotional Characteristics . . . . 12

III METHODS $\ldots \ldots \ldots \ldots \ldots \ldots \ldots \ldots \ldots \ldots \ldots \ldots$

General Plan of Study $\ldots \ldots \ldots \ldots \ldots \ldots \ldots$

Subjects . . . . . . . . . . . . . . 19

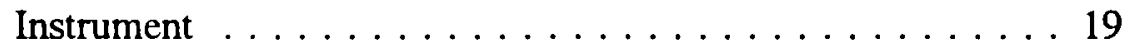

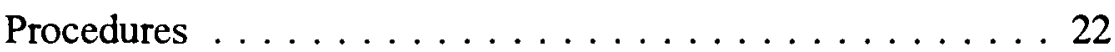

Data Scoring and Analysis . . . . . . . . . . 23

IV RESULTS AND DISCUSSION $\ldots \ldots \ldots \ldots \ldots \ldots \ldots 25$

Results .....................25

Discussion . . . . . . . . . . . . . . . 29 29 


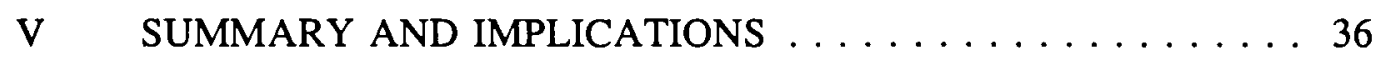

Summary $\ldots \ldots \ldots \ldots \ldots \ldots \ldots \ldots$

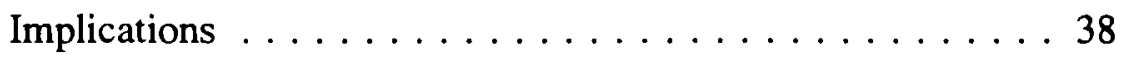

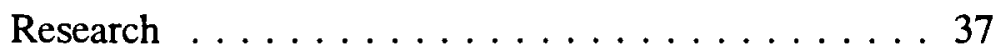

Clinical .................... 39

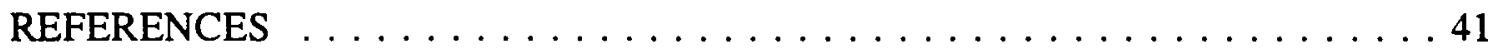

\section{APPENDICES}

A Consent Form for Subjects' Parental Consent and Informed Consent . . . . . . . . . . . . . . . 43

B Affective Behavior Scales for the Disabled-Modified . . . . . . . 46

C Affective Behavior Scales for the Disabled-Modified Raw Total and Subscale Scores for the Traditional Articulation Intervention Group $\ldots \ldots \ldots . \ldots . \ldots 9$

D Affective Behavior Scales for the Disabled-Modified Raw Total and Subscale Scores for the Phonological Cycling Intervention Group $\ldots \ldots \ldots \ldots \ldots$

E Affective Behavior Scales for the Disabled-Modified Mean Total and Subscale Scores for the Traditional Articulation Intervention Group

F Affective Behavior Scales for the Disabled-Modified Mean Total and Subscale Scores for the Phonological Cycling Intervention Group 


\section{LIST OF TABLES}

PAGE

\section{TABLE}

1. Items on Five Subscales of the Affective Behavior Scales for the Disabled-Modified

2. Difference from Pre- to Post-Intervention ABSD-Modified Mean

Subscale Scores Within the Traditional Articulation

Intervention Group $\ldots \ldots \ldots \ldots$

3. Difference from Pre- to Post-Intervention ABSD-Modified Mean

Subscale Scores Within the Phonological Cycling

Intervention Group $\ldots \ldots \ldots \ldots \ldots \ldots$

4. Difference from Pre- to Post-Intervention ABSD-Modified Mean

Subscale Scores Within the Traditional Intervention

Group and the Cycling Intervention Group . . . . . . . . . 29

5. Pre- to Post-Test Raw Score Differences for Individual

Subjects . . . . . . . . . . . . . . . 32 


\section{CHAPTER I}

\section{INTRODUCTION AND STATEMENT OF PURPOSE}

\section{Introduction}

Speech-language pathologists understand how to assess accurately and provide intervention services for children with articulation/phonological disorders. There are numerous reports of successful treatment programs such as the traditional phoneme-oriented approach developed by Van Riper (Van Riper \& Emerick, 1990) and the phonological cycling approach devised by Hodson (Hodson \& Paden, 1991), based on conventional articulation tests and phonological pattem assessments, respectively. Few studies reporting on empirical data regarding the relative effectiveness of these two major intervention approaches have appeared in the literature. As a result of this lack of findings and the increasing demand for treatment efficacy data, a group treatment study is being conducted by Buckendorf (1995) to compare the traditional approach with the cycling approach.

Communication involves the transmission and reception of a message from one person to another, and may be influenced by social and emotional factors. The effects of speech and language intervention services on social and emotional domains have seldom been studied even though the self-concept of children with communication disorders has been of interest for many years. 
According to Van Riper and Emerick (1990), children with communication disorders may experience varying degrees of negative emotions. The rejection that children with communication disorders may experience from peers or within a family can produce mental stress, personal difficulties, and feelings of self-worthlessness. Children with communication disorders may soon realize that other children can produce speech sounds correctly and they cannot. This experience potentially can have a tremendous impact on children and can affect their lives in many domains.

According to Dale (1991), parent report is a valuable way to obtain information about a child and that child's characteristics. A tool that is completed by parents has been developed for assessing social and emotional characteristics of children with disabilities. The Affective Behavior Scale for the Disabled (ABSD, Brannan, 1991) is an instrument that uses parent report to measure social and emotional domains in children, youth, and young adults with disabilities. The ABSD was designed to use with parents/caregivers as respondents to evaluate the impact of intervention programs on their children.

This investigator's review of the literature revealed no empirical research reported that focused directly on social and emotional characteristics in relation to articulation/phonological intervention or social and emotional characteristics in relation to parent report. Therefore, it would be useful to obtain information about social and emotional characteristics in children who are receiving articulation/phonological intervention in order to assess the effectiveness of various treatment approaches from the perspective of social and emotional characteristics. 


\section{Statement of Purpose}

The purpose of this study was to determine whether or not articulation/ phonological intervention influences children's social and emotional characteristics as perceived by their parents, and if so, which articulation approach in treating children with speech sound disorders (traditional vs. phonological cycling) results in more improvement in different domains of social and emotional characteristics. The specific social and emotional characteristics explored in this study are social skills, communication, independence, self-esteem, and domestic responsibility as assessed by the ABSD.

The subjects for this study were part of a larger study conducted to compare two articulation approaches (Buckendorf, 1995). The subjects' parents provided the information necessary to decide whether or not there is a difference in social and emotional characteristics prior to and following articulation/phonological intervention.

The questions posed for this research are: (a) Do children receiving traditional articulation intervention improve in the five different domains of social and emotional characteristics as perceived by their parents, (b) Do children receiving phonological cycling intervention improve in the five different domains of social and emotional characteristics as perceived by their parents, and (c) Is there a difference in the amount of change in social and emotional characteristics between the two articulation approaches for the children receiving articulation/phonological intervention?

These research questions can be stated as null hypotheses: (a) there is no significant improvement in social and emotional characteristics in children receiving 
traditional articulation intervention, (b) there is no significant improvement in social and emotional characteristics in children receiving cycling articulation intervention, and (c) there is no difference in the amount of improvement between children receiving traditional articulation intervention and those receiving phonological cycling intervention.

The corresponding research hypotheses are: (a) children receiving traditional articulation intervention show significant improvement in social and emotional characteristics, (b) children receiving phonological cycling intervention show significant improvement in social and emotional characteristics, and (c) there is a difference in the amount of improvement in a comparison of children receiving traditional articulation intervention and those receiving phonological cycling intervention. 


\section{CHAPTER II}

\section{REVIEW OF THE LITERATURE}

In this chapter, traditional and phonological approaches for examining sound acquisition and phonological development are described, as well as assessment procedures associated with these approaches. Issues regarding how communication disorders influence children's social and emotional characteristics and a brief description of available assessment tools are also addressed.

\section{Traditional Speech Sound Analysis}

In the traditional phoneme-oriented approach, target sounds for intervention are generally selected based on sound acquisition normative data. These types of data specify the age levels when individual sounds are acquired, that is, produced correctly as compared to adult standard production. Most clinicians who use the traditional approach direct intervention towards one sound or, at most, two sounds at a time. According to Van Riper and Emerick (1990), traditional articulation intervention encompasses the sequencing of several activities. Sensory-perceptual training is the first step in traditional articulation intervention with a focus on identifying the standard sound and discriminating it from its error through scanning and comparing. The next step encompasses varying and correcting productions of the sound until it is produced correctly. This step helps to strengthen and stabilize correct production. 
Finally, the last step is transferring the new speech skill to everyday communication situations. This process is usually carried out first for the standard sound in isolation, then in syllables, then in words, and finally in sentences.

Numerous assessment tools are available to test sound acquisition through traditional phoneme-oriented methods. For example, the Goldman-Fristoe Test of Articulation (Goldman \& Fristoe, 1969) is a traditional test that elicits one-word, nonimitative responses with one or two sounds in initial, medial, and/or final positions targeted in each word. In this traditional test, individual target sounds are broadly transcribed if misarticulated, denoting omissions, substitutions, distortions, and additions.

\section{Phonological Processes}

The term phonological process is interpreted as the description of functional misarticulations. A phonological process accounts for a child's systematic sound changes that result from the common difficulty a class of sounds or sound sequences

poses for the speech capacity (Tyler, Edwards, \& Saxman, 1987). Phonological process analysis provides a method for identifying children's systematic speech sound error patterns. For example, through the use of the Assessment of Phonological Processes-Revised (APP-R; Hodson, 1986), the phonological deviations that account for a child's misarticulations are identified.

A treatment approach based on phonological deviations analysis involves facilitating the emergence of new sound patterns through treating phonological 
deviations, as opposed to treating separate sound errors (Tyler et al., 1987). The major assumption of a phonological-pattern-based treatment approach is that remediation is maximized through generalization that occurs across the sounds affected by a particular process when only a few sounds undergoing that process are taught. It is assumed that the elimination of a few specific sound errors produces change in the underlying processes accounting for those errors. Therefore, other errors arising from the process may also be eliminated through direct training.

Phonological cycling remediation was designed explicitly for highly unintelligible children (Garn-Nunn, 1986). The primary factor that differentiates this approach from phoneme-oriented articulation programs is that cycles are used to facilitate the development of intelligible speech patterns (Creaghead, Newman, \& Secord, 1989). Cycles are time periods during which all phonological patterns that need remediation are facilitated in succession (Hodson \& Paden, 1991). Phonemes within the targeted patterns are used to facilitate emergence of the respective patterns. The cycles approach closely approximates the way that normal phonological development occurs.

Like traditional testing of speech sounds, phonology may be examined through an elicited or spontaneous sample with words, phrases, or connected speech as the speech output. However, unlike traditional testing, phonology is examined by observing the patterns of sound production rather than individual speech sounds. The APP-R, the test utilized for this research, uses elicited, single-word productions and examines 11 phonological processes (Hodson, 1986). According to Hodson, the 
phonological cycling intervention approach targets on phonological deviations that occur in $40 \%$ or more in the possible contexts on the APP-R.

\section{Effects of Communication Disorders on Social and Emotional Behaviors}

In today's society, the role of communication is critical, and any individual who is not an effective communicator may have many problems. Children who are having difficulties with their communication skills may experience humiliation and frustration that, over time, can negatively impact self-esteem and reduce motivation to work on their speech problem (Ramig \& Bennet, 1995). When implementing intervention services, it is crucial that the attitudes and feelings of children with communication disorders be addressed.

Since the 1950s, Van Riper has written about the emotional state of children with communication disorders. He primarily focused on the self-concept in children with communication disorders before intervention services were delivered. According to Van Riper and Emerick (1990), a communication disorder is no asset to anyone and often leads to penalties from any society that values the ability to communicate effectively. Individuals who are not considered by themselves and others as effective communicators may even feel rejected. A few of the penalties and rejections that any individual with a communication disorder may experience are negative imitative behaviors, curiosity, nicknaming, humorous response, teasing, embarrassed withdraw, impatience, quick rejection or exclusion, overprotection, pity, misinterpretation, and condescension (Van Riper \& Emerick, 1990). The amount and the kind of penalty 
directed towards individuals who are experiencing communication disorders seem to be dependent on four factors: (a) noticeablitity or peculiarity of the differences; (b) attitude towards their own differences; (c) sensitivities, maladjustments, or preconceived attitudes of the people who penalize them; and (d) presence of other personality aspects (Van Riper \& Emerick, 1990).

Another potential issue with individuals who have communication disorders is the level of frustration they may experience. Frustration is often experienced when human potential is blocked from fulfillment (Van Riper \& Emerick, 1990). Even though the lives of all people are filled with varying degrees of frustration, for some people, the barriers presented before them create an overwhelming amount of frustration. Frustration may lead to anger and aggression and this can in turn affect everything else (Van Riper \& Emerick, 1990). This anger and aggression can be displayed by hostility, hurt, hate, or rage.

Anxiety and guilt are also natural reactions to penalty and rejection (Van Riper \& Emerick, 1990). Van Riper and Emerick (1990) contended that one of the negative aspects of anxiety is that it is usually destructive and consequently does not assist learning or speech intervention. Rather it can only distract, negate, or undermine self-esteem. When speech becomes associated with anxiety, the role of the speech-language pathologist may be challenging. The idea of speech intervention and its "stigma" potentially may negatively impact children with communication disorders and their progress in the clinic setting. 
Like anxiety, guilt also contributes to a part of the "invisible handicap" that often accompanies a communication disorder (Van Riper \& Emerick, 1990). Even if guilt is in the form of regret or embarrassment, it can create various degrees of discomfort for children with communication disorders (Van Riper \& Emerick, 1990).

Children's emotional responses to their communication disorder may vary. Some children with severe speech difficulties show little hostility, and yet some children with mild or minor difficulties show much. One child may have much anxiety or guilt, but little hostility; another may reveal quite the opposite. Some children just seem to "roll with the punches" of the frustrations and manage to adapt with a minimal amount of emotional response (Van Riper \& Emerick, 1990, p. 16.). Experienced speech-language pathologists realize that they may be the target of the child's contained emotions upon receiving intervention services. Speech-language pathologists should not react personally to the child's outward expression of negative emotions. Instead, speech-language pathologists should provide a safe and supportive environment in which the child can self-correct and make progress (Van Riper \& Emerick, 1990). This, in turn, may influence the child to acknowledge the negative emotions. The child can then change negative "thinking" patterns into positive "thinking" patterns (Ramig \& Bennet, 1995). That is a crucial component in the intervention program for these children. However, there are no empirical data to document the social and emotional affects of speech intervention on children who have difficulties communicating. 
Although no published research on children with communication disorders was found in this investigator's literature review, some work has been done on children with learning disorders. According to Kloomok and Cosden (1994), the self-concept of children with learning disabilities varies across different domains, such as social and emotional areas, as well as in their academic performance. From their literature review, Kloomok and Cosden noted reports that these children appear to demonstrate reciprocal effects between academic and emotional functioning. For example, continued academic failures are likely to contribute to low self-concept. At the same time, children with low self-concept may not attempt tasks at which they could be successful (Kloomok \& Cosden, 1994).

For some individuals, self-worth may also be determined by achievements in relation to aspirations (Kloomok \& Cosden, 1994). To understand an individual's self-worth, it is necessary to consider, not only the individual's perceived competence in an area, but also the importance they place on doing well in that area. According to Kloomok and Cosden (1994), some children with learning disabilities may rate themselves as less competent in their scholastic abilities than students without learning disabilities, but not always less competent in self-worth domains that are not related to academics.

Even though the study done by Kloomok and Cosden (1994) focused on children with learning disabilities, the information provided about self-concept is important. People come to value themselves as they are perceived by significant others, and the developing self-images of young children are particularly vulnerable. 
Self-concept can be influenced by many situations and that includes difficulties with communication. Communication disorders can cause distress in an individual's life which in turn can create negative emotions. Thus, self-concept is an issue of importance that should be addressed with sensitivity and awareness in any individual, especially an individual with a disability or disorder.

\section{Assessment of Social and Emotional Characteristics}

The increasing number of studies on self-concept is a reflection of the reemphasis on noncognitive outcomes of education. Most self-concept studies examine correlations between a measure of self-concept and measures of other constructs. The variety of constructs often provide important insights into the factors that motivate children in and out of school as well as into alternative courses of action that may enhance the children's self-concept.

Observation, self-report, parent report, and teacher report are examples of the methods being used in educational research, evaluation, or both, to determine self-concept in children with and without disabilities. However, no empirical research was found in the literature that specifically focused on self-concept or social and emotional behavior in children with communication disorders.

Several studies have been conducted to determine social and emotional behaviors in children with hearing impairments in educational settings. The Meadow Kendall Social-Emotional Assessment (MKSEAI; Meadow, 1980) is often utilized for that purpose. The MKSEAI provides information relating to social adjustment, 
self-image, and emotional adjustment (Meadow, 1980). The instrument contains 58 items. For each statement, the individual's teacher rates the student on a 4-point scale indicating how accurate the teacher feels the statement is reflective of the student.

The Vineland Social Maturity Scale (Doll, 1965) is a tool developed to assess typical maturation of an individual by observation. It provides a definite outline of detailed performances with respect to which children show a progressive capacity for looking after themselves and for participating in that activities which lead forward to ultimate independence as an adult (Doll, 1965). The items on the scale are arranged in order of increasing average difficulty and represent progressive maturation in self-help, self-direction, locomotion, occupation, communication, and social relations. The scale contains 117 items and is categorized in subsets by age equivalents.

There are several tools utilized to measure self-concept through self-report. For example, the Self-Esteem Inventory (SEI; Coopersmith, 1981) has been used as a measure of general self-concept. The SEI was designed to assess self-esteem through the evaluation that the individual makes and customarily maintains with regard to self. Self-esteem may be expressed as attitudes of approval or disapproval that can indicate the extent to which individuals believe themselves to be capable, significant, successful, and worthy. It is a subjective experience that the individual conveys to others by verbal reports and other overt expressive behaviors (Coopersmith, 1981). The SEI contains 50 items that form the self-concept measure. The items are simple, self-descriptive statements such as I give in very easily (Coopersmith, 1981). The two response alternatives for each item are Like me or Unlike me (Coopersmith, 1981). In 
addition to a total self-esteem score, four subscale scores have been identified conceptually: General Self-Concept, Social Self-Peers, Home Parents, and School Academics (Coopersmith, 1981).

Another example of self-report is the How I See Myself Scale (HISM; Gordon, 1968). The HISM is used primarily to measure changes in certain aspects of self-concept resulting from intervention programs. It assesses self-concept or the organization of all the child's biological and environmental experiences as they have been interpreted into one highly organized, highly integrated, multifaceted system (Gordon, 1968). There are two forms of the HISM: the elementary form (ages 3-6 years) and the secondary form (ages 7-12 years). Both forms are comprised of simple, self-evaluative statements. The statements are arranged on 5-point, bipolar scales such as "I do well in school work ... I do not do well in school work" (elementary form) or "I do well in school . . I do not do well in school" (secondary form) (Gordon, 1968).

A final example of self-report is the Michigan State Self-Concept of Ability Scale (SCA; Brookover, Erickson, \& Joiner, 1967). The SCA is a measure of self-concept in academic ability, that is, the behavior individuals indicate to themselves (publicly or privately) about their ability to achieve in academic tasks as compared with others engaged in the same task (Brookover et al., 1967). The SCA-General Scale (Form A) consists of eight items, selected to differentiate students on achievements. The items are self-evaluative questions about academic ability, such as "What kinds of grades do you think you are capable of getting in the following 
subjects?" (Brookover et al., 1967). For each of the four academic subjects (mathematics, English, social studies, and science), there are five response alternatives ranging from "Mostly A's" to "Mostly F's" (Brookover et al., 1967). The SCA-Specific Subjects Scale (Form B) was constructed for the same items with separate responses requested for mathematics, English, social studies, and science (Brookover et al., 1967).

Parent report is a valuable method through which information can be acquired about self-concept in children with and without disabilities. Parents can supply useful knowledge about how their children are functioning and interacting in their environment. For example, parent report can provide information on early childhood development for clinical and research purposes. When carefully assessed and analyzed, parent report can provide a helpful overall evaluation of children. Parent report has continued to be a major methodology for assessing the development of children.

The limitation most frequently discussed is the parents' ability to provide accurate reports (Dale, 1991). Most parents do not have specialized training in speech and language development and display a natural pride that can create bias (Dale, Bates, Reznick, \& Morisset, 1989). It has been almost universally recognized, however, that parents have far more experience with their children than other observers and can produce a more comprehensive estimate of their children's abilities (Dale et al., 1989). 
According to Dale (1991), the report of parents may be less structured than direct clinical observation. Dale (1991) pointed out that parental report is likely to reflect what a child knows, whereas direct observation may reflect behaviors that the child is more likely to use. Parent report is cost effective for a rapid general evaluation of child development. Parent report can also be completed without interfering with the child's assessment process. As Dale (1991) perceptively indicated, because parent report is based on behavior in contexts outside of the clinic, it is especially valuable for monitoring changes that result from intervention.

An example of parent report is the Affective Behavior Scales for the Disabled (ABSD), an instrument used to assess affective growth in populations of campers with disabilities and mild to severe levels of functioning (Brannan, 1991). The ABSD is a questionnaire with a design using parents or caregivers as respondents in order to evaluate the impact (i.e., generalization) of camping, and to overcome communication problems commonly encountered in evaluating camp program effects with the severely disabled (Brannan, 1991). In consideration that over a 10 year period the ABSD items were generated by parents of children and youth with disabilities, one would expect parents would find it east to understand and use. Positive social and emotional benefits have been demonstrated for campers with mild to severe disabilities as a result of exposure to outdoor residential camping. According to Brannan (1991), parents participated as the "experts" in judging the extent to which positive changes in camper behavior generalized to home and community settings. 
Although this tool was developed to assess the effects of camping, it has excellent potential for use in other intervention settings (Brannan, 1991). 


\section{CHAPTER III}

\section{METHODS}

\section{General Plan of Study}

This study was designed to investigate whether or not articulation/phonological intervention influences children's social and emotional characteristics as perceived by their parents. As a part of a larger study (Buckendorf, 1995), two groups of children received articulation/phonological intervention. One group was comprised of children receiving the traditional approach for articulation/phonological disorders, and the other group was comprised of children receiving the cycling approach for articulation/phonological disorders.

Each of the subject's parents was given a rating scale of social and emotional characteristics to complete for their child. At the beginning of intervention and after 20 weeks of intervention for each group, the scores from five domains (social skills, communication, independence, self-esteem, and domestic responsibility) examined through the ABSD-Modified were compared for differences prior to and following intervention. Additionally, the amount of improvement for those social and emotional characteristics was compared between the two groups receiving articulation/phonological intervention. 


\section{Subjects}

The subjects for this study were those selected to participate in the Buckendorf (1995) study comparing two articulation/phonological treatment approaches. Eleven clients who had no previous speech and language services participated in that treatment study. Each client was randomly assigned to one of two groups, with five receiving traditional articulation/phonological treatment and six receiving the phonological cycling approach. At the beginning of the study, all of the clients were between the ages of 3:3 (years, months) and 5:3. Each client demonstrated typical receptive language development by scoring within normal limits on the Test of Auditory Comprehension of Language-Revised (Carrow-Woolfolk, 1985) and the Peabody Picture Vocabulary Test-Revised (Dunn \& Dunn, 1981). Each client had no known neurological impairments. Each client was also categorized as having a severe phonological disorder based on an average percentage of phonological deviation between $40 \%$ and 59\% on the Assessment of Phonological Processes-Revised (APP-R; Hodson, 1986). Each of the parents of the children who participated in this study signed a letter of informed consent (Appendix A).

\section{Instrument}

The instrument used for the study of parent perception of their child's social and emotional characteristics was a 45 -item ordinal rating scale adapted from the Affective Behavior Scales for the Disabled (ABSD; Brannan, 1991). The ABSD was adapted for this study by using all of the items in the subscales for five domains and 
omitting the five items in the sixth subscale that is labeled leisure (Appendix B). This skills adapted version will be referred to as the ABSD-Modified. There are 11 items in the social skills subscale, 9 items in the communication subscale, 9 items in the independence subscale, 9 items in the self-esteem subscale, and 7 items in the domestic responsibility subscale (See Table 1).

\section{TABLE 1}

\section{ITEMS ON Five SubSCALES OF THE AFFECTIVE BeHAVIOR SCALES FOR THE DISABLED-MODIFIED}

\begin{tabular}{||l|l||}
\hline SOCIAL: & COMMUNICATION: \\
Tries to get along with others & Communicates own needs \\
Cooperative & Initiates conversations \\
Aware of others' feelings & Likes to talk about own achievements \\
Willingly helps out & Enjoys interacting with others \\
Listens attentively to others & Willingly shares own experiences \\
Considerate of others & Likes to share own feelings \\
Kind & Expresses own opinion \\
Makes new friends & Outgoing \\
Loyal & Enjoys communicating with others \\
Willingly shares with others & \\
Accepts suggestions for own improvement & \\
\hline INDEPENDENCE: & SELF-ESTEEM: \\
Adapts during separation from the family & Self-confident \\
Enjoys own leisure time & Feels good about self \\
Entertains self without parental help & Enthusiastic/eager to participate \\
Relies on self rather than asking for help & Happy \\
Independent & Motivated/self-starter \\
Seems more mature & Shows pride in own accomplishments \\
Enjoys a happy/favorite pastime & Easy going/relaxed \\
Plans own leisure time & Self-esteem is high \\
Makes own choices for using leisure time & Positive attitude \\
\hline DOMESTIC RESPONSIBILITY: & \\
Voluntarily helps around the house & \\
Helps with chores & \\
Helps with meals & \\
Takes care of own belongings & \\
Keeps own room neat & \\
Is on time & \\
Completes assigned tasks & \\
\hline
\end{tabular}


The ABSD is an instrument designed to evaluate the social and emotional characteristics of children, adolescents, and young adults with disabilities. It is a 50-item rating scale validated in Oregon to assess the affective growth of campers with mild to severe disabling conditions served in residential camp programs (Brannan, 1991). The ABSD is a factor-analyzed instrument with six reliable subscales: socialization, communication, independence, leisure, domestic responsibility, and self-esteem. It is designed for parents or caregivers to rate their children on a 4 -point rating scale $(0=$ never; $1=$ sometimes; $2=$ often; and $3=$ always) for 50 descriptors.

The ABSD has a strong empirical base to support its validity (Brannan, 1991). The content validity of its six subscales was established over a 10 -year period. The ABSD examines more than one domain of affective behaviors and it was developed specifically for children and youth with disabilities. The content validity was established by (a) obtaining items derived from responses to open-ended evaluative questions asked of parents or caregivers of campers with disabilities attending Mt. Hood Kiwanis Camp and Meadowwood Spring Speech Camp; (b) analyzing and categorizing those responses according to descriptors common to the affective domain; and (c) evaluating and refining parent-generated items through the application of expert opinion of professionals from the fields of special education, psychology, measurement and research, and therapeutic recreation.

Subsequent pilot and field testing of the ABSD in the residential camp programs in Oregon serving the disabled established its construct validity using factor 
analytic methods (Brannan, 1991). The data analysis determined the instrument to be highly internally consistent. Total scale internal consistency using Cromback's 1951 Alpha coefficient, subscales, internal consistencies of subscales, and item-factor loadings have also been established (Brannan, 1991).

In conclusion, the procedural steps in the development of the ABSD point to the establishment of content validity. Factor analysis results also point to good construct validity, and significant positive pre- to post-camp changes argue for the sensitivity of the instrument to treatment effects (Brannan, 1991). This instrument, unlike other instruments, examines more than one domain of affective behaviors and was designed specifically for children with disabilities. Results from the field testing of the ABSD indicate that it seems well suited as a tool for evaluating the affective growth of individuals ( 5 to 21 years of age) with disabilities in outdoor recreation programs, with potential suitability for educational settings.

\section{Procedures}

Prior to articulation/phonological treatment, the parents of each of the 11 subjects were given the 45-item rating scale, the ABSD-Modified, designed to measure their perception of their children's social and emotional characteristics in five domains. The clients were seen for 20 weeks, each receiving either the traditional articulation approach or the phonological cycling approach throughout the course of intervention. The articulation/phonological intervention followed treatment protocols specified by the investigator of the larger study. The parents were given the same 
scale after the articulation/phonological treatment study was completed. Thus, the parents of the subjects were given the scale during the first week of articulation/phonological treatment and during the last week of articulation/phonological treatment.

\section{Data Scoring and Analysis}

To analyze the data and determine if differences existed in social and emotional characteristics prior to and following articulation/phonological intervention, the total scales and the five individual subscales of the ABSD-Modified were analyzed. The total raw score for the ABSD-Modified was the mean rating of the 45-items. The subscale raw scores were the mean ratings for each subscale. For example, scores for the social skills subscale were calculated by adding the ratings for the 11 social skills items and dividing by 11 . The amount of improvement was determined by the difference between the pre- and post-scores on the five individual subscales of the ABSD-Modified.

$T$-tests for Paired Samples was used to test the first two hypotheses, that is, (a) children receiving traditional articulation intervention show significant improvement in social and emotional characteristics, and (b) children receiving phonological cycling intervention show significant improvement in social and emotional characteristics. Due to the small sample size, it was necessary to confirm the results of the t-tests for Paired Samples by using the Wilcoxon Matched-Pairs Signed Ranks 
Test non-parametric measure on the pre- and post-ABSD-Modified total scale and subscales.

$T$-tests for Independent Samples of Group was used to test the third hypothesis for the total scales and the individual subscales, that is, there is a difference in the amount of improvement in a comparison of children receiving traditional articulation intervention and those receiving phonological cycling intervention. Due to the small sample size, it was necessary to confirm the results of the $t$-tests for Independent Samples of Group by using the Mann-Whitney U - Wilcoxon Rank Sum W Test non-parametric measure on the pre- and post-ABSD-Modified total scale and subscales. The tests were used with a statistical significance set at the .05 level of confidence for all data analysis. 


\section{CHAPTER IV}

\section{RESULTS AND DISCUSSION}

\section{Results}

This study investigated the possible influence of articulation/phonological intervention on children's social and emotional characteristics. A questionnaire regarding social and emotional characteristics was administered to the parents of the subjects pre- and post-intervention services.

The first research question posed was: Do children receiving traditional articulation intervention improve in five domains of social and emotional characteristics as perceived by their parents? In order to address this research question, the mean of difference from pre- to post-intervention social and emotional characteristics subscale scores within the traditional articulation intervention group were compared with both parametric and non-parametric statistical analysis. $T$-tests for paired samples, a parametric measure, was applied to determine if a difference within the traditional articulation intervention group exists. The resulting two-tailed probability $(p)$ value for each of the five subscales (i.e., social, responsibility, self-esteem, communication, and independence) within the traditional articulation intervention group did not show statistically significant differences from pre- to post-intervention services. Refer to Table 2 for data analysis summary. Due to the 
small sample size, the Wilcoxon Matched Pairs Signed-Ranks Test, a non-parametric analysis, was used to confirm the parametric findings. This non-parametric measure indicated similar results (social, $p=.79$; responsibility, $p=.36$; self-esteem, $p=.59$; communication, $p=.28$; independence, $p=.79$ ) showing no statistically significant difference from pre- to post-intervention subscale scores.

\section{TABLE 2}

DifFERENCE FROM PRE- TO POST-INTERVENTION ABSD-MOdifiEd MEAN SUBSCALE SCORES WITHIN THE TRADITIONAL ARTICULATION INTERVENTION GROUP $(N=5)$

\begin{tabular}{||l|c|c|c|c|c|c|c||}
\hline Subscale Domains & $\begin{array}{c}\text { Pre-Test } \\
M\end{array}$ & $S D$ & $\begin{array}{c}\text { Post-Test } \\
M\end{array}$ & $S D$ & $d f$ & $t$-value & $p$-value* \\
\hline Social & 1.91 & .59 & 1.87 & .41 & 4 & .20 & .849 \\
Responsibility & 1.48 & .39 & 1.60 & .38 & 4 & -.93 & .405 \\
Self-Esteem & 2.18 & .45 & 2.24 & .14 & 4 & -.43 & .690 \\
Communication & 2.13 & .55 & 2.29 & .40 & 4 & -1.09 & .338 \\
Independence & 1.89 & .50 & 1.93 & .32 & 4 & -.23 & .833 \\
\hline
\end{tabular}

Note: ${ }^{*} p<.05$, two-tailed.

The second research question posed was: Do children receiving phonological cycling intervention improve in five domains of social and emotional characteristics as perceived by their parents? In order to address this research question, the mean of difference from pre- to post-intervention social and emotional characteristics subscale scores within the phonological cycling intervention group were compared. T-tests for paired samples was applied to determine if a difference within the phonological cycling intervention group exists. The resulting two-tailed $p$-value for each of the five subscales (i.e., social, responsibility, self-esteem, communication, and independence) 
within the phonological cycling intervention group did not show statistically significant differences from pre- to post-intervention services. However, the $p$-values for the domains of self-esteem $(p=.097)$ and communication $(p=.091)$ were tending toward the significant level of .05 . Refer to Table 3 for data analysis summary. The Wilcoxon Matched Pairs Signed-Ranks Test non-parametric measure also indicated similar results (social, $p=.75$; responsibility, $p=.35$; self-esteem, $p=.12$;

communication, $p=.12$; independence, $p=.27$ ), showing no statistically significant difference from pre- to post-intervention subscale scores.

\section{TABLE 3}

DIFFERENCE FROM PRE- TO POST-INTERVENTION ABSD-MOdifiEd MEAN SUbSCALE Scores Within the Phonological CyCling INTERvention Group $(N=6)$

\begin{tabular}{|l|c|c|c|c|c|c|c||}
\hline Subscale Domains & $\begin{array}{c}\text { Pre-Test } \\
M\end{array}$ & $S D$ & $\begin{array}{c}\text { Post-Test } \\
M\end{array}$ & $S D$ & $d f$ & $t$-value & $p$-value* \\
\hline Social & 1.68 & .51 & 1.79 & .51 & 5 & -.43 & .684 \\
Responsibility & 1.05 & .30 & 1.31 & .68 & 5 & -.73 & .498 \\
Self-Esteem & 1.70 & .49 & 2.18 & .43 & 5 & -2.04 & .097 \\
Communication & 1.72 & .45 & 2.28 & .76 & 5 & -2.09 & .091 \\
Independence & 1.80 & .51 & 1.96 & .47 & 5 & -.93 & .394 \\
\hline
\end{tabular}

Note: ${ }^{*} p<.05$, two-tailed.

The third research question posed was: Is there a difference in the amount of change in social and emotional characteristics between the two articulation approaches for the children receiving articulation/phonological intervention. This question addressed the difference from pre- to post-subscale scores between the traditional articulation intervention group and the phonological cycling intervention group. 
$T$-tests for independent samples of group was used to determine the difference in social and emotional characteristics between the two groups. The Levene's Test for Equality of Variances was performed in conjunction with the $t$-tests for independent samples in order to assess the equality of variance. Once the variances were considered to be equivalent, the $t$-test for equality of means was performed to calculate the amount of difference between the two groups. The amount of difference between the two groups for each of the five subscale scores did not reach a statistically significant difference. Therefore, no significant difference from pre- to post-intervention subscale scores was found between the traditional articulation intervention group and the phonological cycling intervention group. Refer to Table 4 for data analysis summary. The Wilcoxon Matched Pairs Signed-Ranks Test non-parametric measure also indicated no statistically significant difference from preto post-intervention subscale scores between the two groups (social difference, $p=$ .52 ; responsibility difference, $p=.14$; self-esteem difference, $p=.17$; communication difference $p=.27$; independence difference $p=.58$ ).

In conclusion, no evidence was reported to reject the null hypotheses which are: (a) there is no significant improvement in social and emotional characteristics in children receiving traditional articulation intervention, (b) there is no significant improvement in social and emotional characteristics in children receiving cycling articulation intervention, and (c) there is no difference in the amount of improvement between children receiving traditional articulation intervention and those receiving phonological cycling intervention. 
TABLE 4

DifFerenCE FROM PRE- To POST-INTERVENTION ABSD-MOdifIEd MEAN SUBSCALE SCORES WITHIN THE TRADITIONAL INTERVENTION GROUP $(N=5)$

AND THE CYCLING INTERVENTION GROUP $(N=6)$

\begin{tabular}{|l|c|c|c|c|c|c|c||}
\hline Subscale Domains & $\begin{array}{c}\text { Pre-Test } \\
M\end{array}$ & $S D$ & $\begin{array}{c}\text { Post-Test } \\
M\end{array}$ & $S D$ & $d f$ & $t$-value & $p$-value \\
\hline Social & -.04 & .40 & .11 & .61 & 9 & .45 & .663 \\
Responsibility & .12 & .27 & .26 & .88 & 9 & .36 & .728 \\
Self-Esteem & .06 & .32 & .48 & .65 & 9 & 1.40 & .195 \\
Communication & .16 & .35 & .56 & .44 & 9 & 1.25 & .245 \\
Independence & .06 & .44 & .16 & .44 & 9 & .46 & .657 \\
\hline
\end{tabular}

Note: ${ }^{*} p<.05$, two-tailed.

In conclusion, no evidence was reported to reject the null hypotheses which are: (a) there is no significant improvement in social and emotional characteristics in children receiving traditional articulation intervention, (b) there is no significant improvement in social and emotional characteristics in children receiving cycling articulation intervention, and (c) there is no difference in the amount of improvement between children receiving traditional articulation intervention and those receiving phonological cycling intervention.

\section{Discussion}

In examining the significant difference from pre- to post-intervention subscale scores for the two articulation/phonological approaches, it is clear there was no statistically significant change in social and emotional characteristics for the traditional articulation intervention group nor for the phonological cycling 
intervention group. It is also clear there was no statistically significant difference in the amount of improvement between the two articulation/phonological treatment techniques. These results may be because of the small number of subjects used in this study. In order to show a statistically significant difference in total and subscale scores, more subjects are needed to conduct this research.

One explanation for the nonsignificant findings is that the children truly did not improve in the social/emotional domains concomitantly with the intervention. Alternatively, perhaps the ABSD-Modified was not sensitive to changes in social/emotional behaviors that occur as a result of articulation/phonological intervention for preschool children. The ABSD was originally designed to evaluate the positive affect of children, youth, and young adults with disabilities and thus may not have been an inappropriate tool for this investigation due to the preschool age range of the research subjects. Certainly, while many of the items seem appropriate for the subjects, a few of the items seem not to be appropriate. For example, in the domain of responsibility, the item is on time may not have been applicable to the age range of the research subjects.

There are external factors that could have influenced the outcome of this study. For example, the questionnaire was completed by the parents of each subject before and after the intervention services. Perhaps a different parent filled out the preintervention questionnaire than the one who completed the post-intervention questionnaire. For this study, it was confirmed that, in one case, the mother completed the pre-intervention questionnaire and the father completed the 
post-intervention questionnaire. This may have influenced the interpretation of the items rated on the ABSD-Modified. Providing more specific instructions to the individual (i.e., same individual complete the pre- and post-intervention questionnaire) would be necessary to conduct similar studies in the future.

Another factor to consider is the amount of time each subject receives intervention services. The dissertation study conducted by Buckendorf (1995) specified that each subject receive one hour a week of intervention services for a total 20 weeks. The 20-week intervention period was sufficient to see a positive influence on the articulation/phonological skills for some subjects (Buckendorf 1995); however, it may not have been a long enough time period to influence the subjects' social and emotional characteristics. Intervention services may need to be provided for a longer period of time and/or more frequently throughout the week in order to determine whether or not articulation/phonological intervention positively influences children's social and emotional characteristics.

Prior to the completion of this study, it was expected that there would be an improvement in at least some of the social and emotional domains, specifically, self-esteem and communication, of children receiving either the traditional approach or the cycling approach to intervention. However, the results from the data analysis did not show statistically significant differences for the traditional articulation intervention group nor for phonological cycling intervention group. Table 5 displays the pre- to post-test raw score differences for individual subjects. Although the significant level was not reached for either group, visual inspection of the data 
suggests that individual variations occurred in total and subscale scores for each subject in the traditional articulation intervention group (Appendix C) and in the phonological cycling intervention group (Appendix D).

TABLE 5

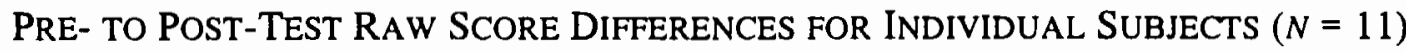

\begin{tabular}{||c|c|c|c|c|c|c|c||}
\hline Subject & Group & Social & Responsible & $\begin{array}{c}\text { Self- } \\
\text { Esteem }\end{array}$ & Communication & Independence & Total \\
\hline 1 & TA & 1 & 0 & 2 & 3 & 7 & 13 \\
2 & TA & -4 & -2 & -1 & -2 & -1 & -10 \\
3 & TA & 3 & 3 & 4 & 2 & 1 & 13 \\
4 & TA & 4 & 2 & 2 & 5 & -2 & 11 \\
5 & TA & -6 & 1 & -4 & -1 & -3 & -13 \\
6 & PC & 2 & 8 & 12 & 6 & 5 & 33 \\
7 & PC & 7 & 4 & 5 & 11 & -4 & 23 \\
8 & PC & 5 & 2 & 7 & 12 & 7 & 33 \\
9 & PC & -6 & 4 & -1 & 2 & 0 & -1 \\
10 & PC & 7 & 3 & 5 & -1 & 1 & 15 \\
11 & PC & -8 & -10 & -2 & 4 & 0 & 16 \\
\hline
\end{tabular}

Note. $\mathrm{TA}=$ Traditional Articulation Intervention Group; $\mathrm{PC}=$ Phonological Cycling Intervention Group.

Some of the subject's pre- to post-intervention scores increased, a few instances of no change occurred, and some scores decreased in the two groups of articulation/phonological intervention. In the traditional articulation group, one subject (subject 3) improved in all five subscale scores from pre- to post-intervention services and in the phonological cycling group, two subjects (subjects 6 and 8) improved in all five domains from pre- to post-intervention services. One subject (subject 2), in the traditional articulation group, decreased in all domains assessed for unknown reasons. 
The ABSD-Modified consists of a 4-point rating scale which is equivalent to never ( 0 points), sometimes ( 1 point), often ( 2 points), and always ( 3 points). The pre- and post-test mean scale scores represent the point rating achieved by each subject in the traditional articulation group (Appendix E) and the phonological cycling group (Appendix F). The majority of the scores fell in the sometimes and often categories, both pre- and post-test. Therefore, there is a possibility for further improvement in the social/emotional domains explored in this study. For example, in the domain of social, the pre-test mean score for subject 1 in the traditional articulation group is 1.18 (sometimes). The post-test mean score for subject 1 in the traditional articulation group is 1.27 (sometimes). The difference between the two mean scores for the social domain is .09 which shows a slight improvement in the sometimes category. None of the subjects in the traditional articulation group showed an improvement of one or more points which would indicate moving from one category to another. In a few of the domains, two subjects in the phonological cycling group showed a 1-point improvement.

Prior to the completion of this study, it was expected that there would be an improvement in social and emotional characteristics between the two articulation/phonological intervention groups. It was expected to see a greater improvement in the phonological cycling intervention group due to the fact that the cycling approach targets more phonemes which may result in a greater amount of improvement in speech intelligibility (Buckendorf, 1995) and thus possibly influence social and emotional characteristics. 
The majority of subjects who participated in this study improved in overall total scores. Seven of 11 subjects made overall positive gains in total scores from preto post-intervention services. It is interesting to note that the overall total scores for the phonological cycling group were higher than the overall total scores for the traditional articulation group. In the traditional articulation group, subjects 1 and 4 improved overall total scores in this study and increased intelligibility in the larger study conducted by Buckendorf (1995). In the phonological cycling group, subjects 6 , 7 , and 10 improved overall total scores in this study as well as increased intelligibility in the study conducted by Buckendorf (1995).

The literature presented by Van Riper \& Emerick (1990) predicted a change would occur in the domains of self-esteem and communication as a result of intervention services. It is interesting to note that in some of the subjects, pre- to post-intervention scores increased, a few instances of no change occurred, and some scores decreased in the two groups of articulation/phonological intervention. In the traditional articulation group, one subject (subject 3) improved in all five subscale scores from pre- to post-intervention services and in the phonological cycling group, two subjects (subjects 6 and 8) improved in all five domains from pre- to post-intervention services. One subject (subject 2) in the traditional articulation group decreased in all domains assessed for unknown reasons.

In the phonological cycling intervention group, there were trends toward the statistically significant level for the domains of self-esteem and communication (Table 3 ) as indicated by $p<.10$. The individual subscale scores indicate that overall from 
pre- to post-intervention services, 7 of 11 subjects showed improvement in self-esteem and 8 of 11 subjects showed improvement in communication. This study does lend some support to Van Riper and Emerick's predicted change because of the trends that occurred in these two domains for the phonological cycling intervention group.

In the domain of social, the individual subscale scores indicate that overall 7 subjects showed improvement for pre- to post-intervention services. In the domain of responsibility, the individual subscale scores indicate that overall 8 subjects showed improvement for pre- to post-intervention services. In the domain of independence, the individual subscale scores indicate that five subjects showed overall improvement for pre- to post-intervention services. However, the amount of improvement seen in each of these three domains (i.e., social, responsibility, and independence) were not as great as the amount of improvement and trends seen in the two domains of self-esteem and communication. 


\section{CHAPTER V}

\section{SUMMARY AND IMPLICATIONS}

\section{Summary}

It would be useful to obtain information about social and emotional characteristics in children who are receiving articulation/phonological intervention in order to assess the effectiveness of various treatment approaches from a social/emotional perspective. The purpose of this study was to determine whether or not articulation/phonological intervention influences children's social and emotional characteristics as perceived by their parents, and if so, which articulation approach (traditional vs. phonological cycling) results in more improvement in different domains of social and emotional characteristics. The specific social and emotional characteristics explored in this study are social skills, communication, independence, self-esteem, and domestic responsibility as assessed by the Affective Behavior Scales for the Disabled-Modified (ABSD-Modified, Brannan, 1991).

In this study, each of the subject's parents completed a rating scale of social and emotional characteristics of their child at the beginning of intervention and again after 20 weeks of intervention. The scores for the five social and emotional domains were compared for differences prior to and following intervention. Additionally, the amount of improvement for those social and emotional characteristics was compared 
between the two groups, one group receiving traditional articulation intervention and the other group receiving a phonological cycling approach.

Data analysis revealed no statistically significant difference between pre- and post-intervention subscale scores for the traditional articulation intervention group and for the phonological cycling intervention group combined. The results also indicated no statistically significant difference in the amount of change in social and emotional characteristics between the two groups of subjects. However, the research data did show trends toward the statistically significant level of .05 in the social/emotional domains of self-esteem $(p=.097)$ and communication $(p=.091)$ for the phonological cycling group. Trends toward the statistically significant level in the two domains of self-esteem and communication suggest that articulation/phonological intervention may influence other areas in the individual's life. Therefore, further investigation of the research questions posed for this study is warranted.

\section{Implications}

\section{$\underline{\text { Research }}$}

There are factors within the design of this study that could be altered which may positively influence conclusions in future research. For example, it is recommended the number of subjects who participate in future research about the effects of communication disorders on social and emotional characteristics be increased. Eleven subjects did not show a statistically significant difference in pre- to post-intervention total and subscale scores for the two articulation/phonological 
groups; more subjects would aid in determining if there really is no improvement in social/emotional characteristics due to articulation/intervention or if more subjects would increase the statistically significant values. The study could also be conducted with subjects who are older in age. The ABSD-Modified could be used with subjects who are older than 3 to 5 years of age because the original ABSD was designed for children, youth, and young adults.

The ABSD-Modified did provide important information about parent perception of their child's social and emotional characteristics. However, the information obtained from the ABSD-Modified did not show statistically significant differences in pre- to post-intervention total and subscale scores for the two articulation/phonological groups. The ABSD-Modified could be reviewed by the subject's parents and/or experts in the field of early childhood development prior to conducting future research about the effects of communication disorders on social and emotional characteristics. The parents and/or experts could examine the age appropriateness of the items in the five domains on the ABSD-Modified. Therefore, this research could be conducted in the future with a more modified version of the ABSD suitable for preschool subjects.

A different evaluation tool could be used to gather the same information on social and emotional characteristics which may indicate different results for the preto post-intervention total and subscale scores in the two articulation/phonological groups. Perhaps the mother and father of each subject could complete a separate preand post-intervention questionnaire. These questionnaires could be compared for 
differences in the five domains (i.e., social, responsibility, self-esteem, communication, and independence) of social and emotional characteristics as perceived by each parent.

Another procedure for data intake could be direct observation of each subject. This could include an interview with each subject and administering the questionnaire directly to the subject. Direct interaction with each subject may provide more information that could aid in determining whether or not social and emotional characteristics are influenced by articulation/phonological intervention.

\section{$\underline{\text { Clinical }}$}

In future clinical experiences, perhaps the phonological cycling approach to articulation/phonological intervention could be used when addressing social/emotional characteristics in children who have a communication disorder. The phonological cycling approach is suggested because the research data did show trends toward the statistically significant level of .05 in the domains of self-esteem $(p=.097)$ and communication $(p=.091)$. Trends toward the statistically significant level in the two domains of self-esteem and communication may suggest that the phonological cycling approach possibly influences social/emotional characteristics.

It is of interest to clinicians to address the issue of consumer satisfaction by attending to the whole person in treatment settings as opposed to treating just the disorder. The relationship between the client and clinician can positively influence the outcome of intervention services when the clinician acknowledges that the reason the individual is receiving intervention services may or may not effect other areas in the 
individual's life such as social/emotional characteristics. Even though the statistically significant level of .05 was not reached in this study, the trends seen in the domains of self-esteem and communication suggest that articulation/phonological intervention may influence other areas in the individual's life such as social/emotional characteristics.

Therefore, when implementing intervention services, it is crucial that the attitudes and feelings of children with communication disorders be addressed. 


\section{REFERENCES}

Brannan, S. A. (1991). The affective behavior scales for the disabled. Unpublished manuscript, Portland State University in Portland, OR.

Brookover, W. B., Erickson, E. L., \& Joiner, L. M. (1967). Self-concept of ability and school achievement III: Relationship of self-concept to achievement in high school. East Lansing, MI: Educational Publications Services.

Buckendorf, R. (1995). An investigation of the effectiveness of two intervention approaches for highly unintelligible children. Unpublished doctoral propectus, The Wichita State University, Wichita, KS.

Carrow-Woolfolk, E. (1985). Test of auditory comprehension of language-revised. Allen, TX: DLM Teaching Resources.

Coopersmith, S. (1981). Self-esteem inventories manual. Palo Alto, CA: Consulting Psychologists Press.

Creaghead, N. A. , Newman, P. W. , \& Secord, W. A. (1989). Assessment and remediation of articulatory and phonological disorders (2nd ed.). Columbus, $\mathrm{OH}$ : Merrill Publishing Company.

Dale, P. S. (1991) . The validity of parent report measure of vocabulary and syntax at 24 months. Journal of Speech and Hearing Research, 34, 565-571.

Dale, P. S., Bates, E., Reznick, S. J., \& Morisset, C. (1989). The validity of a parent report instrument of child language at twenty months. Journal of Child Language, 16, 239-249.

Doll, E. A. (1965). Vineland social maturity scale. Circle Pines, MN: American Guidance Service, Inc.

Dunn, L. M., \& Dunn, L. M. (1981). Peabody picture vocabulary test-revised. Circle Pines, MN: American Guidance Service.

Garn-Nunn, P. G. (1986). Phonological processes and conventional articulation tests: Considerations for analysis. Language, Speech, and Hearing Services in Schools, 17, 244-252. 
Goldman, R. , \& Fristoe, M. (1969). Goldman-Fristoe test of articulation. Circle Pines, MN: American Guidance Service.

Gordon, I. J. (1968). How I see myself scale test manual. Gainesville, FL: Educational Research and Development Council.

Hodson, B. W. (1986). Assessment of phonological processes-revised. Danville, IL: Interstate Printers \& Publishers, Inc.

Hodson, B. W., \& Paden, E. P. (1991). Targeting intelligible speech (2nd ed.) Austin, TX: Pro-Ed.

Kloomok, S., \& Cosden, M. (1994). Self-concept in children with learning disabilities: The relationship between global self-concept, academic "discounting," nonacademic self-concept, and perceived social support. Learning Disabilities Quarterly, 17, 140-153.

Meadow, K. (1980). Meadow/Kendall social-emotional assessment inventory for deaf students. Washington, DC: Gallaudet College.

Ramig, P. R., \& Bennett, E. M. (1995). Working with 7- to 12-year-old children who stutter: Ideas for intervention in the public schools. Language, Speech, and Hearing Services in Schools, 26, 138-150.

Tyler, A. A. , Edwards, M. L. , \& Saxman, J. H. (1987). Clinical application of two phonologically based treatment procedures. Journal of Speech and Hearing Disorders, 52, 393-409.

Van Riper, C., \& Emerick, L. (1990). Speech correction: An introduction to speech pathology and audiology. Englewood Cliffs, NJ: Prentice-Hall. 


\section{APPENDIX A}

CONSENT FORM FOR SUBJECTS' PARENTAL CONSENT and

\section{INFORMED CONSENT}




\section{CONSENT FORM FOR SUBJECTS' PARENTAL CONSENT}

To the parents of

My name is Tracy Carlisle. I am a graduate student at Portland State University studying Speech-Language Pathology. I am currently working on my thesis project under the direction of Dr. Mary Gordon-Brannan. We are researching the positives effects of articulation/ phonological intervention in children ages 3 years to 5 years of age.

Bob Buckendorf is conducting a study comparing two articulation/phonological treatment techniques in children ages three years to five years old. He has agreed to allow me to participate in his study. My participation not only includes actual hands-on work with the children by providing intervention services but also administering a 45-item questionnaire to the parents of the children in the study. The questionnaire is a rating scale of social and emotional characteristics that may describe your child. In addition, at the end of each term and upon completion of the intervention program, I will administer the same questionnaire. This will help me to determine whether or not the intervention program had a positive effect on the children who participated in the study. Thank you for your time and consideration.

Sincerely,

Tracy Carlisle 


\section{INFORMED CONSENT}

$\mathrm{I}$, hereby agree to serve as a subject in the research project to determine whether or not articulation/phonological intervention influences children's social and emotional characteristics. The project will be conducted by Tracy Carlisle, a graduate student in Speech-Language Pathology, and directed by Mary Gordon-Brannan, Program Director, Speech and Hearing Sciences.

I understand that the study involves providing information about my child's social and emotional characteristics. I further understand that I will fill out a 45-item rating scale questionnaire about my child 4 times throughout the study. I understand that there are no risks or hazards involved in the study, but I may be inconvenienced in terms of the time (approximately 15 minutes) it will take to fill out the questionnaire.

It has been explained to me that the purpose of the study is to learn whether or not articulation/phonological intervention influences children's social and emotional characteristics.

I may not receive any direct benefit from my participation in this study, but my participation may help to increase knowledge which may benefit others in the future.

Tracy Carlisle has offered to answer any questions I may have about the study and what is expected of me. I have been assured that all information I give will be kept confidential and that the identity of all subjects, including my child, will remain confidential.

I understand that participation in this study is voluntary. I also understand that I am free to withdraw from participation in this study at any time without jeopardizing my relationship with Portland State University.

I have read and understand the foregoing information.

Date Signature

If you experience problems that are the result of your participation in this study, please contact the secretary of the Human Subjects Research Review Committee, Office of Graduate Studies and Research, 105 Newberger Hall, Portland State University, P.O. Box 751, Portland, Oregon 97207 (503) 725-3423. 
APPENDIX B

AFFECTIVE BEHAVIOR SCALES FOR THE DISABLED-MODIFIED 
Instructions: Please rate each of the statements below from 0 (never) observed to 3 (always) observed. Circle the number that best represents your observations about the characteristics of your child.

1. Tries to get along with others

Never Sometimes Often Always

2. Voluntarily helps around the house.

$\begin{array}{llll}0 & 1 & 2 & 3\end{array}$

3. Self-confident

0

1

4. Communicates own needs

5. Adapts during separate from family

6. Helps with the chores

7. Initiates conversations

8. Enjoys own leisure time

9. Feels good about himself/herself

10. Cooperative

11. Aware of others' feelings

12. Likes to talk about own achievements

13. Willingly helps others

14. Helps with meals

15. Listens attentively to others

16. Entertains self without parent help

17. Enthusiastic/eager to participate

18. Happy
19. Relies on self rather than asking for help

$\begin{array}{llll}0 & 2 & 3\end{array}$

$\begin{array}{llll}0 & 1 & 2 & 3\end{array}$

$\begin{array}{llll}0 & 1 & 2 & 3\end{array}$

$\begin{array}{llll}0 & 1 & 2 & 3\end{array}$

$\begin{array}{llll}0 & 1 & 2 & 3\end{array}$

$\begin{array}{llll}0 & 1 & 2 & 3\end{array}$




Never Sometimes Often Always

22. Considerate of others

$\begin{array}{llll}0 & 1 & 2 & 3\end{array}$

23. Willingly shares own experiences

$\begin{array}{llll}0 & 1 & 2 & 3\end{array}$

24. Independent

0

23

25. Kind

26. Motivated, a self-starter

0

0

2

3

27. Seems more mature

28. Likes to share own feelings

0

29. Makes new friends

30. Shows pride in own accomplishments

31. Enjoys a hobby/favorite pastime

32. Keeps own room neat

33. Loyal

34. Expresses own opinion

35. Easygoing/relaxed

36. Willingly shares with others

37. Plans own leisure time

38. Self-esteem is high

39. Is on time

40. Outgoing

41. Enjoys communicating with others

42. Makes own choices for using leisure time

0




\section{APPENDIX C}

AFFECTIVE BEHAVIOR SCALES FOR THE DISABLED-MODIFIED RAW TOTAL AND SUBSCALE SCORES FOR THE TRADITIONAL ARTICULATION INTERVENTION GROUP 
Affective Behavior Scales for the Disabled-Modified Raw Total and Subscale Scores for the Traditional

Articulation Intervention Group

\begin{tabular}{|c|c|c|c|c|c|c|}
\hline \multicolumn{7}{|c|}{ PRE-TEST } \\
\hline Subject & Social & Responsibility & $\begin{array}{c}\text { Self- } \\
\text { Esteem }\end{array}$ & Communication & Independence & TOTAL \\
\hline 1 & 13 & 08 & 18 & 21 & 13 & 73 \\
2 & 22 & 12 & 20 & 20 & 17 & 91 \\
3 & 19 & 07 & 15 & 26 & 12 & 69 \\
4 & 20 & 12 & 19 & 13 & 21 & 85 \\
5 & 31 & 13 & 26 & 26 & 22 & 108 \\
\hline
\end{tabular}

\begin{tabular}{|c|c|c|c|c|c|c|}
\hline \multicolumn{7}{|c|}{ POST-TEST } \\
\hline Subject & Social & Responsibility & $\begin{array}{c}\text { Self- } \\
\text { Esteem }\end{array}$ & Communication & Independence & TOTAL \\
\hline 1 & 14 & 08 & 20 & 24 & 20 & 86 \\
2 & 18 & 10 & 19 & 18 & 16 & 81 \\
3 & 22 & 10 & 19 & 18 & 13 & 82 \\
4 & 24 & 14 & 21 & 18 & 19 & 96 \\
5 & 25 & 14 & 22 & 25 & 19 & 105 \\
\hline
\end{tabular}




\section{APPENDIX D}

\section{AFFECTIVE BEHAVIOR SCALES FOR THE DISABLED-MODIFIED RAW TOTAL AND SUBSCALE SCORES FOR THE PHONOLOGICAL CYCLING INTERVENTION GROUP}


Affective Behavior Scales for the Disabled-Modified Raw Total and Subscale Scores for the Phonological

Cycling Intervention Group

\begin{tabular}{|c|c|c|c|c|c|c|}
\hline \multicolumn{7}{|c|}{ PRE-TEST } \\
\hline Subject & Social & Responsibility & $\begin{array}{c}\text { Self- } \\
\text { Esteem }\end{array}$ & Communication & Independence & TOTAL \\
\hline 6 & 27 & 07 & 09 & 19 & 16 & 78 \\
7 & 15 & 06 & 18 & 16 & 24 & 79 \\
8 & 15 & 05 & 14 & 10 & 14 & 58 \\
9 & 19 & 08 & 13 & 13 & 10 & 63 \\
10 & 12 & 07 & 16 & 14 & 17 & 66 \\
11 & 23 & 11 & 22 & 21 & 16 & 93 \\
\hline
\end{tabular}

\begin{tabular}{|c|c|c|c|c|c|c|}
\hline \multicolumn{7}{|c|}{ POST-TEST } \\
\hline Subject & Social & Responsibility & $\begin{array}{c}\text { Self- } \\
\text { Esteem }\end{array}$ & Communication & Independence & TOTAL \\
\hline 6 & 29 & 15 & 21 & 25 & 21 & 111 \\
7 & 22 & 10 & 23 & 27 & 20 & 102 \\
8 & 20 & 07 & 21 & 22 & 21 & 91 \\
9 & 13 & 12 & 12 & 11 & 10 & 58 \\
19 & 19 & 10 & 21 & 13 & 18 & 81 \\
11 & 15 & 01 & 20 & 25 & 16 & 77 \\
\hline
\end{tabular}




\title{
APPENDIX E
}

\author{
AFFECTIVE BEHAVIOR SCALES FOR THE \\ DISABLED-MODIFIED MEAN TOTAL AND \\ SUBSCALE SCORES FOR THE \\ TRADITIONAL ARTICULATION \\ INTERVENTION GROUP
}


Affective Behavior Scales for the Disabled-Modified Mean Total and Subscale Scores for the Traditional Articulation Intervention Group

\begin{tabular}{|c|c|c|c|c|c|c|}
\hline \multicolumn{7}{|c|}{ PRE-TEST } \\
\hline Subject & Social & Responsibility & $\begin{array}{c}\text { Self- } \\
\text { Esteem }\end{array}$ & Communication & Independence & TOTAL \\
\hline 1 & 1.18 & 1.14 & 2.00 & 2.33 & 1.44 & 1.62 \\
2 & 2.00 & 1.71 & 2.22 & 2.22 & 1.89 & 2.02 \\
3 & 1.73 & 1.00 & 1.67 & 1.78 & 1.33 & 1.53 \\
4 & 1.82 & 1.71 & 2.11 & 1.44 & 2.33 & 1.89 \\
5 & 2.82 & 1.86 & 2.89 & 2.89 & 2.44 & 2.41 \\
\hline
\end{tabular}

\begin{tabular}{|c|c|c|c|c|c|c|}
\hline \multicolumn{7}{|c|}{ POST-TEST } \\
\hline Subject & Social & Responsibility & $\begin{array}{c}\text { Self- } \\
\text { Esteem }\end{array}$ & Communication & Independence & TOTAL \\
\hline 1 & 1.27 & 1.14 & 2.22 & 2.67 & 2.22 & 1.91 \\
2 & 1.64 & 1.43 & 2.11 & 2.00 & 1.78 & 1.80 \\
3 & 2.00 & 1.43 & 2.11 & 2.00 & 1.44 & 1.82 \\
4 & 2.18 & 2.00 & 2.33 & 2.00 & 2.11 & 2.13 \\
5 & 2.27 & 2.00 & 2.44 & 2.78 & 2.11 & 2.33 \\
\hline
\end{tabular}




\section{APPENDIX F}

AFFECTIVE BEHAVIOR SCALES FOR THE

DISABLED-MODIFIED MEAN TOTAL AND

SUBSCALE SCORES FOR THE

PHONOLOGICAL CYCLING

INTERVENTION GROUP 
Affective Behavior Scales for the Disabled-Modified Mean Total and Subscale Scores for the Phonological

Cycling Intervention Group

\begin{tabular}{|c|c|c|c|c|c|c|}
\hline \multicolumn{7}{|c|}{ PRE-TEST } \\
\hline Subject & Social & Responsibility & $\begin{array}{c}\text { Self- } \\
\text { Esteem }\end{array}$ & Communication & Independence & TOTAL \\
\hline 6 & 2.45 & 1.00 & 1.00 & 2.11 & 1.78 & 1.73 \\
7 & 1.36 & 0.86 & 2.00 & 1.78 & 2.67 & 1.76 \\
8 & 1.36 & 0.14 & 1.56 & 1.11 & 1.56 & 1.29 \\
9 & 1.73 & 1.14 & 1.44 & 1.44 & 1.11 & 1.41 \\
10 & 1.09 & 1.00 & 1.78 & 1.56 & 1.89 & 1.47 \\
11 & 2.09 & 1.57 & 2.44 & 2.33 & 1.78 & 2.07 \\
\hline
\end{tabular}

\begin{tabular}{|c|c|c|c|c|c|c|}
\hline \multicolumn{7}{|c|}{ POST-TEST } \\
\hline Subject & Social & Responsibility & $\begin{array}{c}\text { Self- } \\
\text { Esteem }\end{array}$ & Communication & Independence & TOTAL \\
\hline 6 & 2.64 & 2.14 & 2.33 & 2.78 & 2.33 & 2.47 \\
7 & 2.00 & 1.43 & 2.56 & 3.00 & 2.22 & 2.27 \\
8 & 1.82 & $1.00]$ & 2.33 & 2.44 & 2.33 & 2.02 \\
9 & 1.18 & 1.71 & 1.33 & 1.22 & 1.11 & 1.29 \\
10 & 1.73 & 1.43 & 2.33 & 1.44 & 2.00 & 1.81 \\
11 & 1.37 & 0.14 & 2.22 & 2.78 & 1.78 & 1.71 \\
\hline
\end{tabular}

